\title{
A Case of Sotos Syndrome with Congenital Sacrococcygeal Teratoma
}

\author{
Konjenital Sakrokoksigeal Teratomlu Bir Sotos Sendromu Vakası
}

\author{
Alay $\mathbf{M T}^{\mathbf{1}}$, Kalaycı Yiğin $\mathbf{A}^{\mathbf{1}}$, Özdemir $\mathbf{F}^{\mathbf{1}}$, Gümüş $\mathbf{U}^{\mathbf{1}}$, Ocak $\mathrm{Z}^{\mathbf{2}}$, Seven $\mathbf{M}^{\mathbf{1}}$ \\ 1-İstanbul Üniversitesi-Cerrahpaşa, Cerrahpaşa Tıp Fakültesi, Tibbi Genetik Anabilim Dalı, İstanbul, Türkiye. 2-Yeni Yüzyıl Üniversitesi, \\ Gaziosmanpaşa Hastanesi, Genetik Hastalıklar Tanı Merkezi, İstanbul, Türkiye.
}

\begin{abstract}
Sotos syndrome is one of the most common overgrowth syndromes. It was first described by Juan Sotos in 1964. The incidence has been reported 1: 14,000. Major findings of the diseases include overgrowth associated with advanced bone age, learning disability, and specific facial dysmorphism. Although most of the cases are sporadic, cases with autosomal dominant inheritance have also been reported. The NSD1 gene associated with the disease is localized to the q35 region of chromosome 5. The likelihood of symptoms, such as tumors, hypermetropia, strabismus, and hypoglycemic attacks are quite unlikely. However, it is recommended that all patients be monitored for tumors such as teratoma and neuroblastoma. In this article, we present a rare case of Sacrococcygeal teratoma diagnosed with Sotos syndrome in our center.

ÖZET

Sotos sendromu aşırı büyüme sendromları arasinda yer alır. İlk defa Juan Sotos tarafindan 1964 yllında tanımlanmıştır. Görülme sıklı̆̆ 1:14.000 olarak bildirilmiştir. Hastalığın major bulguları: İlerlemiş kemik yaşının eşlik ettiği aşırı büyüme, ögrenme güçlüğü ve kendine özgü fasial dismorfizmdir. Vakaların çoğu sporadik olmakla birlikte otozomal dominant olarak kalittlan olgular da rapor edilmiştir. Hastallkla iliskilendirilen NSD1 geni 5. Kromozomun q35 bölgesine lokalize olmuștur. Tümör, hipermetropi, strabismus ve hipoglisemik atak gibi bulguların görülme olasılığı oldukça düşüktür. Buna rağmen, bütün hastaların teratom ve nöroblastom gibi tümörler açısından izlenilmesi önerilmektedir. Bu makalede merkezimizde Sotos sendromu tanısı konulan ve nadir görülen Sakrokoksigeal teratomla seyreden bir olgu sunulacaktır.
\end{abstract}

Key Words:

Congenital Teratoma,

Sotos Syndrome,

NSD1 Gene,

Molecular Analyses.

Anahtar Kelimeler:

Konjenital Teratom,

Sotos Sendromu

NSD1 Geni,

Moleküler Analiz.

\section{Gíis}

Sotos sendromu sı görülen aşırı büyüme sendromlarından birisidir. İlk defa Juan Sotos tarafından 1964 yılında tanımlanmıştır. Hastalığın görülme sıklığı 1:14.000 olarak kabul edilmektedir. Sotos Sendromunun major bulguları arasında, ilerlemiş kemik yaşının eşlik ettiği aşırı büyüme, hastalığa özgü fasial dismorfizm ve öğrenme güçlüğü yer alır $(1,2,3)$.

Sotos sendromu genellikle de novo mutasyonla oluşmaktadır. Ayrıca ebeveynlerden otozomal dominant kalıtıldığını gösteren vaka raporları da bildirilmiştir (4). Sotos Sendromunun yaklaş1k \%75'inden sorumlu olan ve tümör süpresör genler arasında yer alan NSD1 geni, $5 q 35$ kromozom bölgesine lokalize olup 23 ekzondan oluşmaktadır (4,6). NSD1 geni ile ilgili HGMD (Human Gene Mutation Database) ve LOVD (Leiden Open Variation Database) veritabanlarında 400' den fazla mutasyon tanımlanmış, bu mutasyonların \%35'i küçük veya büyük gen delesyonları, \%25'i yanlış anlamlı (missense), \%20'si anlamsız (nonsense), \%15'i küçük insersiyonlar, \%5'i kesim noktası varyantları ve diğer $\% 5$ ’i ise kompleks yeniden düzenlenmelerden oluşmaktadır (5).

Çocukluk çağında ortaya çıkan yumuşak doku sarkomları nadir görülürken, aşırı büyüme sendromlarında benign ve malign tümör riski artmıştır. Sotos sendromunda nöroblastom, akut miyeloid lösemi, akciğer kanseri, astrositom ve sakrokoksigeal teratom gibi tümörlerin gelişim riski \%2.2-3.9 olarak bildirilmiştir(4). Bu tümörler içinde en sık görüleni sakrokoksigeal teratom olup, konjenital olanlarının daha kötü prognozlu olduğu belirtilmektedir $(7,8)$.

\section{OLGU}

Olgumuz 34 aylık kız çocuğu. Sakrokoksigeal bölgede tespit edilen ve opere edilen kitlenin teratom olarak belirlenmesi üzerine genetik inceleme amaciyla merkezimize refere edildi. Anne baba arasında akrabalık yoktu. Diğer akrabalarında doğumsal anomali ve kalıtsal bir hastalık mevcut değildi. Hastanın, gebeliğin 40 . haftasında 4835 gram ağırlığında, $57 \mathrm{~cm}$ boyunda, $41 \mathrm{~cm}$ baş çevresiyle hastanede sezaryenle dünyaya geldiği, yenidoğan döneminde neonatal pnömoni, beslenme bozukluğu, hipoglisemi ve interkostal çekilmeler nedeniyle yoğun bakım tedavisi uygulandığı, hiperbilirübinemi nedeniyle küvöz bakımına alındığı ve fototerapi yapıldığı, sakrakoksigeal bölgede tespit edilen oluşumun yenidoğan döneminde hemanjiom olarak değerlendirildiği ve MR çekimi ile tümöral kitle olduğuna karar verildiği, tümöral kitlenin 3 aylıkken rezeke edildiği ve patolojik olarak teratom tanısı konulduğu, 12 aylıkken bir kez febril nöbet geçirdiği, gebelik döneminde anne kanında $\alpha$-fetoprotein 


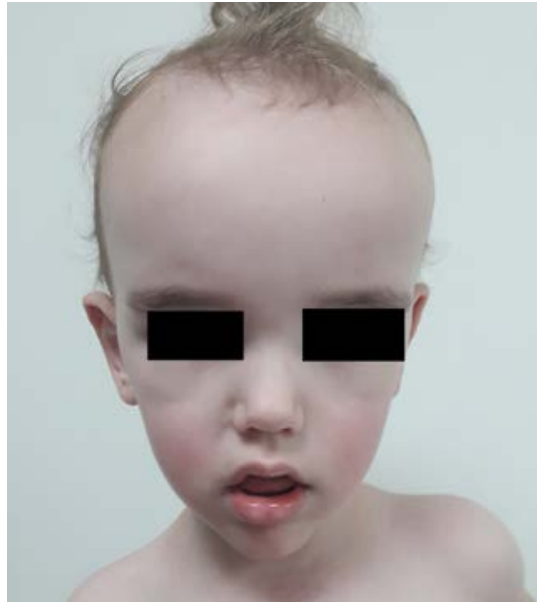

Resim 1: Hastanın yüz görünümü

düzeyinin yüksek bulunduğu belirlendi. Hastanın 9 aylıkken desteksiz oturduğu, 13 aylıkken emeklediği, 22 aylıkken yürüdüğü ifade edildi. Olgumuzun antropometrik ölçümlerinde; boy: $105 \mathrm{~cm}$ (>97p), kilo: $24 \mathrm{~kg}(>97 \mathrm{p})$, baş çevresi: $56 \mathrm{~cm}$ ( $>97 \mathrm{p}$ ) olarak bulundu. Fizik muayenesinde; yüz uzun ve dar, alın geniş ve yüksek, saçlar kestane renginde seyrek ve yumuşak, baş dolikosefal ve makrosefal, alın ve temporal saç çizgisi geride, üçgen yüz görünümü mevcut, gözler derin yerleşimli, hipertelorizm ve strabismus görülmekte, burun küçük ve burun kökü basık, burun delikleri öne bakıyor, ala nasiler iyi gelişmemiş, küçük ve sivri çene, yüksek damak, nisbeten büyük, hafif düşük ve geri yerleşimli kulaklar, bifid tragus, toraksın alt kısmında hafif tipte pektus ekskavatus, üst kısmında pektus karinatus deformitesi mevcut, meme başları ayrık, ayaklar küçük ince ve dar yapılı, içe dönük, pes planus mevcut, bilateral 2.,3. ve 4.parmaklar aynı kökten çıkıyor, sol ayak dorsalinde 1.ile 5. parmak arasında, sağ ayakta ise 2.ile 5. parmak arasında çizgilenme mevcut. El parmakları uzun ve uçları künt olup, dorsal bölgede metakarpofalangieal dimpil saptand1 (Resim 1,2). Kemik yaşı ileri olup, 5 yaşla uyumluydu. Sakral bölgede ameliyat nedbesi vard1. Göz muayenesinde +3.5 derece hipermetropi saptandı. Nöro-motor gelişim basamakları yaşıtlarına göre geri olup, 18 aylıkken tek kelime söyleyebildiği, 27 aylıkken 2-3 kelimelik cümleler kurabildiği belirtildi.

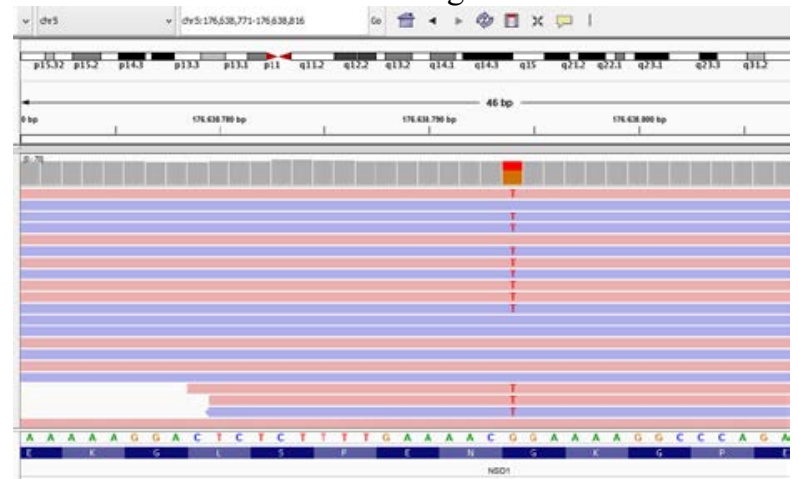

Şekil 1: NSD1 geni 5. ekzonda meydana gelen c.G3394T değişimi

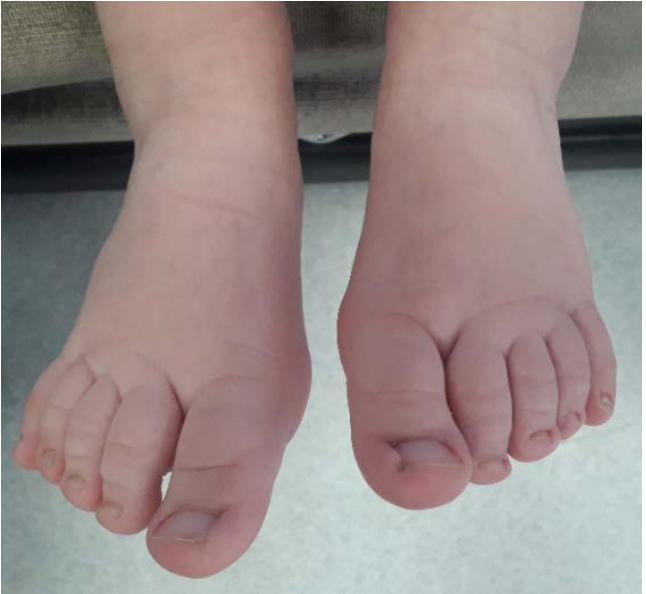

Resim 2: Hastanın ayak görünümü

Denver gelişim testinde; kişisel-sosyal ve dil gelişimi yaşına uygun, kaba motor gelişimi 15-18 ay, ince motor gelişimi 14-21 ayla uyumlu olarak bulundu. Patolojik analizde teratom tanısı konuldu. Hemogram ve rutin biyokimyasal ölçümleri normaldi. BERA normal, Kardiak Ekokardiografi ve Tüm Batın Ultrasonografisinde patolojik bir bulgu saptanmad. Kranial MR'da korpus kallozum hipoplazisi, difüzyon MR'da korpus kallosumda T2'de hiperintensite ve perivasküler mesafenin genişlemiş olduğu görüldü. Uyku EEG'si normaldi. Hastanın sitogenetik analizinde karyotipi normal, moleküler analizinde 5.kromozomun uzun koluna lokalize NSD1 geninin 5. ekzonunda c.G3394T(p.G1132X) varyantı heterozigot olarak tespit edildi (Şekil 1). Bu varyant, in-silico analizlere göre sınıf 1 patojenik, ACMG sinıflandırmasına göre sınıf 2 olası patojenik olarak değerlendirilmektedir.

\section{TARTISMA}

NSD1 genindeki patojenik varyantlar Sotos sendromu ile ilişkili olup, literatürde çoğunlukla otozomal dominant, bazı vakalarda ise resesif kalıtıldığ bildirilmiştir (OMIM: 606681). Olgumuzda tespit edilen varyantın kalıtım modeli otozomal dominant olarak kabul edilmektedir. Sotos Sendromunun major bulguları üç ana başlık altında toplanmaktadır: İlerlemiş kemik yaşının eşlik ettiği aşırı büyüme, öğrenme güçlüğü ve hastalığa özgü fasial dismorfizm. Sotos sendromu, sık görülen aşırı büyüme sendromları arasında yer alır $(1,2)$. $\mathrm{Bu}$ hastaların ayırıcı tanısında; Beckwith-Wiedemann sendromu, Perlman sendromu, Simpson Golabi-Behmel sendromu, Veaver-Smith sendromu, Frajil-X sendromu, Bannayan-Zonana sendromu, Nevo sendromu, Marfan sendromu, homosistinüri ve akromegali yer almaktadır. Simpson-Globi Behmel sendromu, Beckwith Wiedemann ve Perlman sendromunda makrozomi, visseromegali ve makroglossi ön plandadır. SimpsonGlobi Behmel sendromunda alt dudak ya da çenede yarıklanma mevcut olup, buna postaksiyal sindaktili eşlik eder. Sotos sendromunun aksine genitoüriner anomaliler oldukça sık görülür (\%73). Ayrıca vakaların $\% 40$ '1nda diafragma hernisi tespit edilmektedir . Sotos 
sendromunda ise renal anomali sıklığ $1 \% 15$ olup, en s1k vezikoüreteral reflü görülür $(9,10,11)$. Tanıyı dışlamasa da Simpson-Globi Behmel hastalarında genellikle yaş ilerledikçe baş çevresi normal sınırlar içerisinde kalır. Oysa Sotos sendromlu hastalarda yaş ilerledikçe baş çevresi genellikle akranlarına göre daha büyük seyreder. Perlman sendromu otozomal resesif geçiş gösterir ve hastalıkta görülen organomegali ve makrosefaliye rağmen, mikroretrognati de tespit edilirse, bu semptom aşırı büyüme sendromlarının ayırıcı tanısında önemli bir bulgu olarak değerlendirilir (9). Weaver-Smith sendromunda Sotos sendromundan farklı olarak prognati karakteristik olmayıp, eklem kontraktürleri ve kamptodaktili beklenir (9). Hastaların kranial MR'ında ventrikülomegali ve korpus kallozum agenezisi saptanabilmektedir. Bizim hastamızda da korpus kallozum agenezisi mevcuttu. Ayrıca vakaların \% 25'inde ateşli olmayan nöbet geçirme öyküsü bulunmaktadır. Hastamızda epileptik atak olarak kabul edilebilecek bir nöbet öyküsü bulunmuyordu; ancak olgumuzun yenidoğan döneminde beslenmeyle geçen hipoglisemik ataklar geçirdiği ifade edilmektedir. Bu vakalarda strabismus ve hipermetropi nadir görülen bulgular olarak bildirilmektedir (12). Bizim olgumuzda her üç bulgu da mevcuttu.

Sotos sendromlu vakaların yaklaşık \%3'ünde çeşitli tümörler görülür (4). $\mathrm{Bu}$ tümörler arasında nöroblastoma, akut myeloid lösemi, küçük hücreli akciğer kanseri, astrositom ve sakrokoksigeal teratom yer almaktadır. Olgumuzda prenatal başlangıçlı olup postnatal dönemde tanı konulan sakrokoksigeal teratom vardı ve 3 aylıkken opera edilmişti. Sakrokoksigeal teratomların premayotik kökenli olduğu, kaynağını totipotent hücrelerden aldığ1, bu nedenle bütün embriyonik tabakaları içerdiği belirtilmektedir $(7,8)$. Ayrıca, prenatal başlangıçlı teratomların postnatal başlangıçlı teratomlara göre daha kötü prognozlu olduğu $(7,8)$, literatürde; Sotos sendromu ve sakrokoksigeal teratomun birlikte görüldüğü 2000 yılında iki (13), 2019 yılında iki vaka olmak üzere, toplam 4 vaka bildirilmiştir. $\mathrm{Bu}$ tür tümörlerin rastlantısal olabileceği gibi, aşırı büyümenin tümör gelişimini uyarıcı etkisine bağlı olarak da gelişebileceği belirtilmektedir (14).

\section{SONUÇ}

Sonuç olarak; Sotos sendromu tanısı konulan olgumuzda NSD1 geninde tespit edilen heterozigot değişim de novo olup patojenik varyant olarak kabul edildi. NSD1 geninin tümör baskılayıcı bir gen olarak işlev görmesi nedeniyle bu gendeki mutasyonların malignite riskinde artışa neden olabileceği göz önünde bulundurularak hastaların belirli aralıklarla izlenmesi önerilmektedir. Genitoüriner ve iskelet sistemi kontrol edilmeli, teratom harici tümöral gelişim olasılığı da gözden uzak tutulmamalıdır. Sotos sendromunun genetik danışmasında; ailenin diğer bireylerine de genetik test yapılması, bu amaçla bilinen mutasyon açısından taranması ve hastalığın az da olsa diğer nesillerde tekrarlama olasılığı bulunduğu belirtilmelidir. Doğum kilosu normal bebeklere göre daha fazla olan, dismorfik yüz bulguları eşliğinde konjenital sakrokoksigeal teratomu da bulunan vakalarda aşırı büyüme sendromlarından biri olan Sotos Sendromu da tanıda göz önünde bulundurulmalıdır.

Çıkar çatışması

Tüm yazarlar çıkar çatışması olmadığını beyan eder.

\section{KAYNAKLAR}

1. Edmondson AC, Kalish JM. Overgrowth Syndromes. J Pediatr Genet. 2015 Sep;4(3):136-43. DOI: 10.1055/s-0035-1564440.

2. Neri G, Moscarda M. Overgrowth syndromes: a classification. Endocr Dev. 2009; 14:53-60.

3. Sotos JF, Dodge PR, Muirhead DD, Crawford JD, Talbot NB. A syndrome of excessively rapid growth and acromegalic features and a nonprogressive neurologic disorder. N Engl J Med 1964; 271: 109-116.

4. Visser R, Matsumoto N. Genetics of Sotos syndrome. Curr Opin Pediatr 2003;15:598-606.

5. Tatton-Brown K, Cole TRP, Rahman N. Sotos Syndrome. 2004 Dec 17 (Updated 2019 Aug 1). In: Adam MP, Ardinger HH, Pagon RA, et al. editors. GeneReviews. Seattle (WA): University of Washington, Seattle; 1993-2019. Available from: https://www.ncbi.nlm.nih.gov/books/NBK1479/

6. Tatton-Brown K, Douglas J, Coleman K, Baujat G, Cole TR, Das S et al. Childhood Overgrowth Collaboration. Genotype-phenotype associations in Sotos syndrome: an analysis of 266 individuals with NSD1 aberrations. Am J Hum Genet. 2005 Aug;77(2):193-204.

7. Sotos JF, Argente J. Overgrowth disorders associated with tall stature. Adv Pediatr. 2008;55:213-254.

8. Gracia Bouthelier R, Lapunzina P. Follow-up and risk of tumors in overgrowth syndromes. J Pediatr Endocrinol Metab. 2005 Dec;18(Suppl 1):1227-1235.

9. Baujat G, Cormier-Daire V. Sotos syndrome. Orphanet J Rare Dis. 2007 Sep 7;2:36

10. Alessandri JL, Cuillier F, Ramful D, Ernould S, Robin S, de Napoli-Cocci S, Rivière JP, Rossignol S. Perlman syndrome: report, prenatal findings, and review. Am J Med Genet A. 2008 Oct 1;146A(19):2532.

11. Türkmen S, Gillessen-Kaesbach G, Meinecke P, Albrecht B, Neumann LM, Hesse V, Palanduz S, Balg S, Majewski F, Fuchs S, Zschieschang P, Greiwe M, Mennicke K, Kreuz FR, Dehmel HJ, Rodeck B, Kunze J, Tinschert S, Mundlos S, Horn D. Mutations in NSD1 are responsible for Sotos syndrome, but are not a frequent finding in other overgrowth phenotypes. Eur J Hum Genet. 2003;11:858-65.

12. Maino DM, Kofman J, Flynn MF, Lai L. Ocular manifestations of Sotos syndrome. J Am Optom Assoc. 1994 May;65(5):339-46.

13. Leonard NJ, Cole T, Bhargava R, Honoré LH, Watt J. Sacrococcygeal teratoma in two cases of Sotos syndrome. Am J Med Genet. 2000 Nov 13;95(2):182-4.

14. Grand K, Gonzalez-Gandolfi C, Ackermann AM, Aljeaid D, Bedoukian E, Bird LM, et al. Hyperinsulinemic hypoglycemia in seven patients with de novo NSD1 mutations. Am J Med Genet A. 2019 Apr;179(4):542-551. 